\title{
Effect of device-guided paced breathing of biofeedback on blood pressure, stress and anxiety levels in hypertensives
}

\author{
Efeitos de um dispositivo de biofeedback com respiração ritmada sobre a pressão sanguínea, níveis \\ de estresse e ansiedade em hipertensos \\ Efecto de la respiración guiada por dispositivo de biofeedback sobre la presión arterial, el estrés y \\ los niveles de ansiedad en hipertensos
}

Received: 07/21/2021 | Reviewed: 07/25/2021 | Accept: 07/26/2021 | Published: 08/01/2021

\author{
Beatriz Souza de Albuquerque Cacique New York \\ ORCID: https://orcid.org/0000-0001-8303-1280 \\ Federal University of Rio Grande do Norte, Brazil \\ E-mail: bia.hp@ hotmail.com \\ Micaele Farias Nascimento \\ ORCID: https://orcid.org/0000-0003-3001-1125 \\ Paraíba State University, Brazil \\ E-mail: micaele.farias@hotmail.com \\ Alexa Alves de Moraes \\ ORCID: https://orcid.org/0000-0001-6882-3773 \\ Universidade Federal de Viçosa, Brazil \\ E-mail: alexa@ufv.br \\ Jéssica Costa Leite \\ ORCID: https://orcid.org/0000-0002-4726-9416 \\ Campina Grande Medical Sciences Faculty, Brazil \\ E-mail: jessica.leite@ maisunifacisa.com.br \\ Iara Tainá Cordeiro de Souza \\ ORCID: https://orcid.org/0000-0002-2626-9193 \\ Paraíba State University, Brazil \\ E-mail: iaratainacordeiro@gmail.com \\ Ana Tereza do Nascimento Sales Figueiredo Fernandes \\ ORCID: https://orcid.org/0000-0002-5167-3673 \\ Paraíba State University, Brazil \\ E-mail: aninhat.sales@gmail.com
}

\begin{abstract}
The present study aimed to evaluate the influence of cardiac coherence through Biofeedback Therapy (BT) with paced breathing on blood pressure, stress and anxiety levels in individuals with essential arterial hypertension. The participants underwent 8 sessions of paced breathing guided by biofeedback visual therapy for 20 minutes, in which they were evaluated through clinical assessment, Hamilton Anxiety Rating Scale, Perceived Stress Scale and cardiovascular variables. Comparisons of means were performed using the paired and unpaired Student's t-test. Statistically significant correlations were considered when $\mathrm{p} \leq 0.05$ with a $95 \%$ confidence interval. The effect size (Cohen's d) and common language effect size were calculated to assess the effect of such therapy. Sixteen patients with mean age of $57.3 \pm 14$ years old participated in this study. Comparisons between mean initial and final systolic blood pressure levels (SBP) in women ( $\mathrm{p}=0.007$; Cohen's $\mathrm{d}=0.50)$, pre- and post-training heart rate $(\mathrm{p}=0.02$; Cohen's $d=0.60)$ and anxiety levels $(p=0.01$; Cohen's $d=1.04)$ were significant. Comparisons between pre- and post-training SBP $(p=0.006$; Cohen's $d=0.81)$ and pre- and post-training anxiety levels $(p=0.04 ;$ Cohen's $d=0.32)$ were significant among males. In conclusion, paced breathing training with biofeedback therapy can be promising to reduce anxiety levels in individuals with essential arterial hypertension.
\end{abstract}

Keywords: Hypertension; Psychology biofeedback; Cardiac coherence; Psychological stress; Anxiety.

\section{Resumo}

O presente estudo teve como objetivo avaliar a influência da coerência cardíaca por meio da Terapia de Biofeedback (BT) com respiração estimulada sobre a pressão arterial, níveis de estresse e ansiedade em indivíduos com hipertensão arterial essencial. Os participantes foram submetidos a 8 sessões de respiração estimulada guiada por terapia visual de biofeedback por 20 minutos, nas quais foram avaliados por meio de avaliação clínica, Escala de Hamilton para Ansiedade, Escala de Estresse Percebido e variáveis cardiovasculares. As comparações de médias foram realizadas usando o teste $\mathrm{t}$ de Student pareado e não pareado. Correlações estatisticamente significativas foram consideradas quando $\mathrm{p} \leq 0,05$ com intervalo de confiança de $95 \%$. O tamanho do efeito ( $\mathrm{d}$ de Cohen) e o tamanho do efeito da 
linguagem comum foram calculados para avaliar o efeito de tal terapia. Dezesseis pacientes com idade média de 57,3 \pm 14 anos participaram deste estudo. Comparações entre os níveis médios de pressão arterial sistólica (PAS) inicial e final em mulheres $(\mathrm{p}=0,007 ; \mathrm{d}$ de Cohen $=0,50)$, frequência cardíaca pré e pós-treinamento $(\mathrm{p}=0,02 ; \mathrm{d}$ de Cohen $=$ $0,60)$ e níveis de ansiedade $(\mathrm{p}=0,01 ; \mathrm{d}$ de Cohen $=1,04)$ foram significativos. As comparações entre a PAS pré e póstreinamento $(\mathrm{p}=0,006 ; \mathrm{d}$ de Cohen $=0,81)$ e os níveis de ansiedade pré e pós-treinamento $(\mathrm{p}=0,04 ; \mathrm{d}$ de Cohen $=$ 0,32 ) foram significativas entre os homens. Em conclusão, o treinamento respiratório estimulado com terapia de biofeedback pode ser promissor para reduzir os níveis de ansiedade em indivíduos com hipertensão arterial essencial. Palavras-chave: Hipertensão; Biofeedback da psicologia; Coerência cardíaca; Estresse psicológico; Ansiedade.

\section{Resumen}

El presente estudio tiene como objetivo evaluar la influencia de la Terapia de Biofeedback (BT) con la respiración ritmada sobre la presión arterial, el estrés y los niveles de ansiedad en individuos con hipertensión arterial esencial. Los participantes fueron sometidos a 8 sesiones de respiración estimulada guiada por terapia de biorretroalimentación visual durante 20 minutos, en las que fueron evaluados mediante evaluación clínica, Escala de Ansiedad de Hamilton, Escala de Estrés Percibido y variables cardiovasculares. Las comparaciones de medias se realizaron utilizando la prueba $\mathrm{t}$ de Student para datos apareados y no apareados. Se consideraron correlaciones estadísticamente significativas cuando $\mathrm{p} \leq 0.05$ con un intervalo de confianza del 95\%. Se calcularon el tamaño del efecto ( $\mathrm{d}$ de Cohen) y el tamaño del efecto del lenguaje común para evaluar el efecto de dicha terapia. Participaron en este estudio 16 pacientes con una edad media de 57,3 \pm 14 años. Comparaciones entre los niveles medios de presión arterial sistólica (PAS) inicial y final en mujeres $(\mathrm{p}=0,007$; d de Cohen $=0,50)$, frecuencia cardíaca antes y después del entrenamiento $(\mathrm{p}=0,02 ; \mathrm{d}$ de Cohen $=0,60)$ y niveles de ansiedad $(\mathrm{p}=0,01 ; \mathrm{d}$ de Cohen $=1,04)$ fueron significativas. Las comparaciones entre la PAS antes y después del entrenamiento $(\mathrm{p}=0,006 ; \mathrm{d}$ de Cohen $=0,81)$ y los niveles de ansiedad antes y después del entrenamiento $(\mathrm{p}=0,04 ; \mathrm{d}$ de Cohen $=0,32)$ fueron significativas entre los hombres. En conclusión, el entrenamiento respiratorio estimulado con terapia de biorretroalimentación puede ser prometedor para reducir los niveles de ansiedad en personas con hipertensión arterial esencial.

Palabras clave: Hipertensión; Psicología biofeedback; Coherencia cardiaca; Estrés psicológico; Ansiedad.

\section{Introduction}

Arterial hypertension $(\mathrm{AH})$ is a chronic disease displaying multifactorial etiology (Brazilian Society of Cardiology, 2016). Worldwide, an increase of approximately $60 \%$ in hypertensive adults is estimated for 2025 , thus affecting 1.56 billion people (Karney et. al, 2005), causing an adverse impact on cardiovascular mortality and morbidity worldwide (Unger et al., 2020).

Among the determinant risk factors for $\mathrm{AH}$ development, psychosocial factors play a significant role on $\mathrm{AH}$ aggravation, being psychosocial stress and anxiety commonly observed in such population (Whelton et. al, 2018), since the clinical and subclinical levels of these emotional conditions influence biological pathways of the sympathetic nervous system and the hypothalamic-pituitary-adrenal axis, thus interfering in the cascade processes involved in blood pressure (BP) regulation (Trudel-Fitzgerald et. al, 2015).

Studies claim that meditation techniques, behavioral psychotherapies (Bai et. al, 2015; Sharma \& Rush, 2014), relaxation and biofeedback therapy (BT) (Brook et. al, 2013) demonstrate significant effects on these patients, due to their decreasing effects on BP levels (Greenberg et. al, 20088). Such therapies may provide self-regulation of the autonomic nervous system, providing effects on cardiac coherence, i.e., the balance between heart rate (HR) and respiratory rate (RR), as well as on muscle contraction, BP and brain activity (Neto, 2010; Gomes \& Coghi \& Coghi, 2016); moreover, the reduction of anxiety and stress levels are expected. All these events can contribute with a positive influence on BP control (Bhardwaj et. al, 2020).

Recently a meta-analysis breathing exercises (BE) suggested that are effective on BP control in hypertensive patients (Bhardwaj et. al, 2020). The BE can increase baroreflex sensitivity that is able to decrease sympathetic activation. This mechanism makes it possible to regulate blood pressure fluctuations (Cernes \& Zimlichman, 2017).

The use of paced breathing training associated with BT may represent an effective alternative for modulating such disbalance. In view of the high worldwide prevalence of $\mathrm{AH}$ and its elevated costs for health systems, studies that investigate 
the effects of new therapeutic strategies combined with drug therapy are important this study aimed to evaluate the effects of paced breathing guided by BT on BP, stress and anxiety levels in hypertensive individuals.

\section{Methodology}

\section{Study design}

This is a quasi-experimental and analytical study, carried out at the Physiotherapy Department of the State University of Paraíba, Brazil.

\section{Ethics}

The research was authorized by the Research Ethics Committee of Paraíba State University (CAAE: 85670518.0.0000.5187), and each participant was instructed to read and sign a consent form prior to participating.

\section{Participants}

This study comprised individuals aged 18 years or over regardless gender, presenting with stage I or II essential hypertension with a medical diagnosis, currently non-smokers, and who did not have any other associated cardiovascular, respiratory or neurocognitive disorders, nor did not present body mass index (BMI) $>30 \mathrm{~kg} / \mathrm{m}^{2}$. Convenience sampling strategy was adopted in the present study.

\section{Outcome measures}

Participants underwent clinical evaluation, BP, anxiety and stress levels assessment, pulse oximetry and biofeedback training. The clinical evaluation comprised items on personal, socioeconomic, anthropometric and occupational data, besides questions related to the disease. Data were obtained through interviews and reassessed throughout the study when necessary.

Measurement of BP was performed with a Manual Aneroid Sphygmomanometer and Rappaport Premium Stethoscope (Manufacturer Ningbo Jiangbei Tenso Medical Instruments Co., LTD - People's Republic of China). Participants were instructed to rest for 5 minutes, and not to speak during its measurement. In addition, they were asked to empty their bladder, not to drink alcohol or coffee, besides not eating and performing any physical exercise for at least 60 minutes before BP assessment. In accordance to the Brazilian Society of Cardiology (2016) (Brazilian Society of Cardiology, 2016), BP evaluations were carried out with the patients relaxed, seated, legs uncrossed, feet flat on the floor, resting their back against the chair, with the arm supported at the level of the heart and its palm facing upwards.

At least two measurements were carried out, with a one-minute interval between them (Veiga et. al, 2003). American Heart Association (2018) reference values were considered for AH levels stratification (Unger et. al 2020), where stage I hypertension is a systolic blood pressure (SBP) ranging from 130 to $139 \mathrm{mmHg}$ or diastolic blood pressure (DBP) between 80 and $89 \mathrm{mmHg}$; stage II hypertension occurs when SBP $\geq 140 \mathrm{mmHg}$ or DBP $\geq 90 \mathrm{mmHg}$.

Anxiety levels were assessed using the Hamilton Anxiety Rating Scale (Hamilton, 1959), a 14-item instrument divided into two sections: the first one presents 7 items related to psychic symptoms while the second one presents 7 somatic symptoms items. Each item is scored on a scale of 0 (not present) to 4 (severe). The scale was applied before and after 8 biofeedback training sessions. Overall score was obtained by adding each item response value, thus total score ranges from 0 to 56 , where $<17$ points indicate mild- severity anxiety; $18-24=$ mild to moderate severity; $25-30=$ moderate to severe and $>31=$ severe pathological anxiety (Hamilton, 1959). 
Stress levels were verified using the Perceived Stress Scale (PSS-10) by Cohen (Hamilton, 1959; Reis \& Hino \& Añez, 2010). This 10-item scale assesses stress-inducing factors through items regarding situations that occurred in the previous month, such as: inability to control important situations; anger, nervousness and stress; self-confidence to handle problems; and coping with situations out of the person's control. Answers are scored through a 5-point Likert scale 0 (never) to 4 (very often). The score ranges from 0 to 40 , and the higher the score, the greater the individual's perceived stress level.

Pulse Oximetry was evaluated using a portable pulse oximeter (Contec Medical Systems Co, LTD., Model: CMS50D, People's Republic of China) (American Thoracic Society, 2016). The participant was asked to use the device on the index finger in all sessions.

\section{Intervention}

The intervention consisted with sessions of paced breathing guided by a Biofeedback (device guided breathing) (CardioEmotion $®$ Home biofeedback device,NPT - Neuropsicotronics LTDA, São Paulo - Brazil). These devices determines the modulation of cardiac coherence (CC), characterized by the balance between HR and RR. Thus, CC is considered as a state where the heart rate variability (HRV) is maximum and is close to $0.1 \mathrm{Hertz}$ in the HR power spectral density. Previous studies indicated that the lower the sympathetic activation of the autonomic nervous system (lower the HR and the higher the HRV), indicating an individual's good physiological adaptation, which is linked to better survival rates in patients who suffered sudden heart attacks and lethal arrhythmias (Gomes \& Coghi \& Coghi, 2014).

Before the beginning of the training, an assessment and adaptation session were conducted; and after the 8 training sessions, a new assessment was carried out. The 20-minute training sessions occurred twice a week for four weeks, where the easy level training was chosen, audio in "music" and "cardiac coherence state" mode, and the respiratory rhythm was the one through which the patient achieved a better cardiac coherence in the assessment session.

All training sessions were carried out by a single researcher, at scheduled times in the same shift (morning/afternoon) in order to avoid BP fluctuations. A standardized explanation was provided to all participants regarding the biofeedback apparatus and the training protocol.

The device provided the possibility of 5 breathing rate ranges. Mode "A" comprised 6 to 7 breaths per minute, "B" with 5 to 6 breaths per minute, "C" with 5 to 6 breaths per minute, "D" with 4 to 5 breaths per minute and "E" with 3 to 4 breaths per minute. In the initial assessment session, it was determined in which of these modes the patients would achieve the best cardiac coherence performance. The differences between respiratory rates can be explained by the concept of CC, which occurs when there are synchronism and resonance between HR, breathing and the baroreflex rhythm (Respiratory Sinus Arrhythmia - RSA). The RSA modulates the parasympathetic tone and can be visualized through the high frequency of HRV. Decreases between 3-6 respiratory cycles may represent an increase in HRV amplitude is observed, which is influenced by both sympathetic and the parasympathetic system, thus reflecting in the baroreceptor reflex (Gomes \& Coghi \& Coghi, 2014).

After the initial adjustments, a 2-minute adaptation training was held. The choice of the breath mode was performed based on the best patient performance, determined by the CC score in the respiratory frequencies obtained at baseline. Usually, the breath mode in which a greater $\mathrm{CC}$ occurs is breath "C"; however, the other modes could be adopted in case any individual was unable to resonate at such respiratory frequency.

During the training sessions, the patients remained seated, using the finger sensor and looking at the computer screen. They were advised to remain as relaxed as possible, avoiding crossing the limbs and without establishing any dialogue with the researcher. They were instructed to perform deep diaphragmatic breathing (DDB), by inhaling and exhaling slowly and deeply, maintaining control on the air flow in order to follow the frequency determined by the device's floater. 
At the beginning and end of each training session, participants were reassessed for BP, HR, RR, pulse oximetry and $\mathrm{CC}$. The $\mathrm{CC}$ value was measured through the score obtained by the biofeedback device, after training. The $\mathrm{CC}$ grade obtained ranged from 0 to 10 , with 0 being a low $\mathrm{CC}$ and 10 a high $\mathrm{CC}$.

\section{Statistical Analysis}

Statistical analysis was carried out in Graph Pad Prism version 6.0 for Windows. Numerical variables were presented as mean and standard deviation, and categorical variables as frequencies.

The normality was checked using the Kolmogorov-Smirnov test. Comparisons of cardiovascular variables means, stress and anxiety scales and CC score between pre- and post-intervention were carried out through the paired Student's T test. The differences between means were considered statistically significant when $\mathrm{p} \leq 0.05$ with a $95 \%$ confidence interval.

The Effect Size (ES) was calculated using the Cohen's d test, based on the guidelines of Espírito-Santo and Daniel (2015) (Espírito Santo \& Daniel, 2017). The effect reference values adopted for Cohen's d were: insignificant (d <0.19); small $(\mathrm{d}=0.20-0.49)$; medium $(\mathrm{d}=0.50-0.79)$; large $(\mathrm{d}=0.80-1.29)$; very large $(\mathrm{d}>1.30)$. The interpretation from the Common Language Effect Size (ES-CL) was also carried out, in which the effect is converted into a percentage, corresponding to the probability that a person randomly removed from the intervention group will have a higher score than a person removed from control group.

\section{Results and Discussion}

Data collection occurred between May and September 2018. A total of 16 participants ( 9 females), with a mean age of $57.3 \pm 14$ years old, who underwent paced breathing training guided by biofeedback therapy maintaining pharmacological therapy prescribed by a doctor. Only one participant withdrew from the study due to the impossibility of attending the intervention sessions, being excluded from the sample.

An average of $8.7 \pm 5.6$ years from the time of the AH diagnosis was observed and all participants were under antihypertensive drugs administration. Eleven patients reported using only one antihypertensive medication $(M=5, W=6)$, while 5 reported using more than one antihypertensive drug $(\mathrm{M}=2, \mathrm{~W}=3)$. Among the classes of antihypertensive drugs used by the participants, they were angiotensin II receptor blockers (36.66\%), calcium channel blockers (20\%), followed by angiotensin-converting enzyme (ACE) inhibitors (13.33\%), thiazide diuretics (13.33\%), and others (16.66\%). Regarding physical fitness, eleven participants reported being physically active $(M=4, W=4)$, since 1.5 to 13 years ago for men, and 2 to 8 years for women, with a frequency of up to 3 times per week. Further data can be observed in Table 1. 
Table 1. Characteristics of study population.

\begin{tabular}{|c|c|}
\hline Variables & Overall (n=16) \\
\hline Age (years) & $57.3 \pm 14$ \\
\hline Weight (kg) & $71.9 \pm 15$ \\
\hline Height (m) & $1.59 \pm 0.08$ \\
\hline BMI (Kg/m $\left.{ }^{2}\right)$ & $27.8 \pm 3.8$ \\
\hline WC (cm) & $93.6 \pm 13.1$ \\
\hline ISBP $(\mathbf{m m H g})$ & $120 \pm 16$ \\
\hline FSBP (mmHg) & $111 \pm 21$ \\
\hline IDBP (mmHg) & $74.8 \pm 9$ \\
\hline FDBP (mmHg) & $72.1 \pm 8$ \\
\hline IHR (bpm) & $77 \pm 12$ \\
\hline FHR (bpm) & $76 \pm 10$ \\
\hline IRR (irpm) & $14 \pm 2.6$ \\
\hline FRF (irpm) & $14 \pm 2.9$ \\
\hline Schooling (years) & $11.6 \pm 6.2$ \\
\hline PDT (years) & $8.7 \pm 5.6$ \\
\hline Physical activity performance (years) & $2.2 \pm 0.8$ \\
\hline
\end{tabular}

Legend: BMI: Body mass index, WC: Waist circumference, ISBP: Initial systolic blood pressure, FSBP: Final systolic blood pressure, IDBP: Initial diastolic blood pressure, FDBP: Final diastolic blood pressure, IHR: Initial heart rate, FHR: Final heart rate, IRR: Initial respiratory rate, FRR: Final respiratory rate, PDT: Post-diagnostic time. Source: Authors.

After intervention, participants had a reduction in mean SBP $(\mathrm{p}=0.002)$, showing a significant reduction in this variable with medium ES and ES-CL indicating $71.7 \%$ probability hypertensive patients have reduced SBP after an intervention.

Besides, anxiety assessment demonstrated a reduction in the average score obtained at the beginning of the training $(17.2 \pm 9)$ compared to the end $(11 \pm 7)$ with statistical significance and large ES (Cohen's d= 0.92), and the ES-CL indicated that the probability of a hypertensive patients having reduced levels of anxiety after training is $82.1 \%$.

Furthermore, it showed no statistical significance regarding DPB, stress, and CC score (Table 2). However, the means before and after intervention evidenced a reduction of 3.6\% in hypertensives' DBP, a reduction of $13.33 \%$ in hypertensives' stress, besides an increase in CC score of $13.72 \%$ in participants. Presenting an evident reduction in mean anxiety scores after therapy was observed in both women (40\%) and men (31.82\%). Stress scores after intervention decreased by $11.23 \%$ in men and $25.92 \%$ in women. 
Table 2: Effect size of cardiac variables, anxiety and stress among men, women and overall of the study.

\begin{tabular}{|c|c|c|c|c|c|c|c|c|c|c|c|c|c|c|c|}
\hline & \multicolumn{5}{|c|}{ Women $(n=9)$} & \multicolumn{5}{|c|}{$\operatorname{Men}(n=7)$} & \multicolumn{5}{|c|}{ Overall $(n=16)$} \\
\hline Variable & $\begin{array}{c}\text { Pre- } \\
(\mathrm{M} \pm \mathrm{SD})\end{array}$ & $\begin{array}{c}\text { Post- } \\
(\mathrm{M} \pm \mathrm{SD})\end{array}$ & $\mathbf{p}$ & $\begin{array}{c}\text { Cohen's } \\
\text { d }\end{array}$ & $\begin{array}{c}\text { ES-CL } \\
(\%)\end{array}$ & $\begin{array}{c}\text { Pre- } \\
(\mathbf{M} \pm \mathbf{S D})\end{array}$ & $\begin{array}{c}\text { Post- } \\
(\mathrm{M} \pm \mathrm{SD})\end{array}$ & $\mathbf{p}$ & Cohen's d & $\begin{array}{c}\text { ES-CL } \\
(\%)\end{array}$ & $\begin{array}{c}\text { Pre- } \\
(\mathrm{M} \pm \mathrm{SD})\end{array}$ & $\begin{array}{c}\text { Post- } \\
(\mathrm{M} \pm \mathrm{SD})\end{array}$ & $\mathbf{p}$ & Cohen's d & $\begin{array}{c}\text { ES-CL } \\
(\%)\end{array}$ \\
\hline SBP & $122 \pm 18$ & $111 \pm 25$ & $0.007 *$ & 0.59 & 72.3 & $118 \pm 14$ & $113 \pm 15$ & 0.17 & 0.42 & 66.4 & $120 \pm 16$ & $111 \pm 21$ & $0.002 *$ & 0.57 & 71.7 \\
\hline DBP & $75.1 \pm 11$ & $71.5 \pm 10$ & 0.25 & 0.42 & 66.3 & $74.5 \pm 6.5$ & $72.8 \pm 7.5$ & $0.006^{*}$ & 0.30 & 61.6 & $74.8 \pm 9$ & $72.1 \pm 8$ & 0.13 & 0.39 & 65.1 \\
\hline Anxiety & $13 \pm 5$ & $7.8 \pm 5$ & $0.01 *$ & 1.28 & 90.0 & $22 \pm 10$ & $15 \pm 7$ & $0.04 *$ & 0.94 & 82.7 & $17.2 \pm 9$ & $11 \pm 7$ & $0.0009^{*}$ & 0.92 & 82.1 \\
\hline Stress & $13.5 \pm 8$ & $10 \pm 4.8$ & 0.43 & 0.59 & 72.1 & $17.8 \pm 12$ & $15.8 \pm 4$ & 0.68 & 0.20 & 58.1 & $15 \pm 10$ & $13 \pm 5$ & 0.37 & 0.26 & 60.4 \\
\hline $\begin{array}{l}\text { Average } \\
\text { CC score }\end{array}$ & $5.2 \pm 1.9$ & $6.0 \pm 1.7$ & 0.26 & 0.54 & 70.6 & $5.1 \pm 1.6$ & $5.4 \pm 3.0$ & 0.74 & 0.13 & 55.3 & $5.1 \pm 1.7$ & $5.8 \pm 2.3$ & 0.31 & 0.41 & 65.8 \\
\hline
\end{tabular}

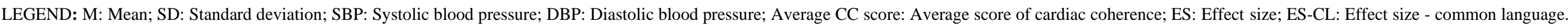
*statistical significance when comparing the means between pre- and post-intervention means. Source: Autohrs. 
The main findings of the present study demonstrate that paced breathing training guided by biofeedback provided a significant reduction in blood pressure levels in both men and women, with large and medium EF, respectively. Additionally, a reduction in stress and anxiety levels was observed, with statistical significance for anxiety scores. These findings demonstrate that the use of alternative therapies can modulate factors that negatively influence BP in hypertensive patients.

The benefits of use of Biofeedback on BP have been verified in previous studies. Palomba et al. (2011) (Palomba et. al, 2011) found a significant decrease in SBP levels, from $140.08 \pm 9.08 \mathrm{mmHg}$ to $129.08 \pm 10.45 \mathrm{mmHg}$, after $4 \mathrm{training}$ sessions $(\mathrm{p}=0.018)$, while the same variables remained unchanged in the control group, demonstrating that even a short-term training protocol can induce significant changes in BP levels. These findings were corroborated by Nolan et al. (2010) (Nolan et. al, 2010), who found significant reductions in daytime SBP $(\mathrm{p}=0.009)$ and 24-hour BP $(\mathrm{p}=0.03)$ after neurocardiac training with biofeedback in hypertensive patients throughout 6 sessions, lasting 1 hour each, for 2 months.

Similar findings were observed by Elavally et al (2020) (Elavally et. al, 2020), who evidenced a BP reduction after BT assisted home based breathing exercises.training. This intervention was carried out comprising 12 sessions during 12 weeks, lasting 20 minutes, in individuals with essential hypertension (stage I hypertension). Fourteen percent of patients in intervention group $(\mathrm{N}=150)$ moved from stage $\mathrm{I}$ to the pre-hypertension stage and $3.3 \%$ in the control group ( $\mathrm{N}=151)$ ( $\mathrm{p}<$ 0.001). Systematic review was conducted and observed that breathing exercise can reduce BP levels in hypertensive patients. Nine studies were included in meta-analyses and comparison between experimental and control group showed significant effect of BE techniques on SBP $(Z=4.82$, p < 0.00001) and DBP $(Z=4.10, p<0.0001)$ control (Bhardwaj et. al, 2020). The changes in cardiovascular variables identified in the previous studies can be explained by the RSA, which is the cardiac pattern that occurs when HR increases in inspiration and decreases during expiration (Lehrer et. al, 2003). In view of this, slow breath increases the baroreflex sensitivity thus influencing HR and BP oscillation (Joseph et. al, 2005; Del Paso et. al, 2006).

With the RSA effect, CC is achieved due to a perfect synchrony between breathing, HR and BP (Moura \& Mendes, 2016). Regardless the HRV level, a high percentage of CC represents an excellent balance between sympathetic and parasympathetic nervous systems, with a parasympathetic predominance (Climov et. al, 2014).

An important finding of the present research was the effect of intevention on CC score and HR, thus influencing on HRV. The scores after training demonstrated CC improvement in both men and women, though without a statistical significance. However, with regards to the percentage of CC during the intervention, better averages were observed in all participants, a relevant finding according to Climov et al (2014). In addition, slow and deep breathing has also been showed to improve baroreflex sensitivity and significantly increases heart rate variability (HRV) in both prehypertensive and hypertensive individuals (Wang et. al, 2010).

With regards to stress levels, the scores obtained demonstrated considerable reduction before and after training, both in men and women. A similar result was found in the study conducted by Reiner (2008) (Reiner, 2008), which examined the effectiveness of a RSA biofeedback device in individuals with anxiety disorders and other autonomic dysfunction-related diseases; biofeedback therapy lasted for 3 weeks and demonstrated significant results in reducing anxiety levels $(p=0.009)$. Similar results were found by Sherlin et al. (2009), who used the same biofeedback device, though the intervention consisted of a single session, in which the participants reported high stress levels on the Perceived Stress Scale and, after such intervention, HR, executive functions and anxiety state presented with a decrease.

A literature review carried out by Yau and Loke (2021) suggests that stress and anxiety level can reduce after protocols that include DDB. Goessl, Curtiss and Hofmann (2017) suggests that biofeedbcak therapy can be a promising and effective technique to treat anxiety and stress symptoms. The findings of the present study evidenced a significant reduction in anxiety scores for women. Contrastingly, the study by Tsai et al. (2007), in which a 4-week training program with HRVB was 
carried out in patients with moderate hypertension, anxiety levels decrease, although no statistical significance was evident for both intervention and control groups ( $p=0.098$ and $p=0.721$, respectively).

Another approach for stress levels was conducted by Fonkoue et al (2018), the authors investigated the effects a protocol with device guided breathing (RESPeRATE- InterCure) upon BP levels, muscle sympathetic nerve activity (MSNA) and sympathetic and cardiovagal BRS in prehypertensive veterans with posttraumatic stress disorder (PTSD). Intervention group ( $\mathrm{N}=13)$ underwent a single $15 \mathrm{~min}$ session of a slow guided breathing ( 5 breaths/min) and sham group ( $\mathrm{N}=10)$ used the same device but at a physiological respiratory rate (around $14 \mathrm{irmp}$ ). The intrevention group showed a decrease in blood pressure levels ( $\mathrm{SBP}, \mathrm{P}<0.001 ; \mathrm{DPB}, \mathrm{P}=0.01)$ and positive results were also seen in MSNA $(\mathrm{P}<0.05)$ and sympathetic BRS $(\mathrm{P}=0.01)$ for the intervention group. Other $\mathrm{BF}$ devices can cause improvement in physiological and psychological factors as seen by Prisloo et al (2011).

The authors aiming at identifying the 10-minute effect of HRVB (heart rate variability biofeedback) after an induced stress state on cognition and anxiety. Thus, intervention was effective for providing relaxation $(p<0.001)$, reducing anxiety ( $p$ $<0.001$ ), improving cognitive performance and HR ( $\mathrm{p}<0.01)$. Anxiety was also addressed by Lee, Kim and Wachholtz (2015), whose study was designed to determine the effect of HRVB treatment versus relaxation training on reducing anxiety in students. Four individual sessions were held, lasting 45 minutes for 2 weeks. Thus, greater and more significant reduction in anxiety levels was observed in the biofeedback group.

A systematic review that evaluated the effects of different BFB devices in the control of blood pressure levels also showed that there was an improvement in the psychosocial aspects involved, such as stress, anxiety, anger control and quality of life (Vital et. al, 2021).

Considering this, biofeedback therapy associated with paced slow breathing is a relevant therapeutic option for the symptomatic modulation of anxiety and stress in hypertensive patients, as their blood pressure conditions are directly dependent on their emotional conditions, which will consequently result in clinical condition gains.

\section{Conclusion}

Limitations of the study are related to patient adherence to complementary therapies for the treatment of hypertension, access to information about complementary therapies by assistant physicians, and also the impossibility of comparisons with a control/placebo group. The main conclusions of the study are: (a) Paced breathing guided by biofeedback can reduce BP levels in patients with essential hypertension in stages I and II as an adjunct to drug therapy; (b) the intervention can reduce stress and anxiety levels, besides (c) improving HRV by providing increased CC and reduced HR.

The results obtained were promising within what is expected for the use of non-drug therapies as a strategy to control $\mathrm{AH}$ and factors that influence BP levels, thus representing a promising treatment in terms of reducing costs with drugs and hospital admissions.

Nevertheless, more studies are needed to emphasize and confirm the effects of such technique, in addition to delimiting the most effective protocols, since there is not a consensus in literature regarding the best parameters to be used.

\section{References}

American Thoracic Society. ATS Patient Education Series (2016) https://www.thoracic.org/patients/patient-resources/resources/portuguese/pulseoximetry.pdf.

Bai, Z., Chang, J., Chen, C., Li, P., Yang, K., \& Chi, I. (2015). Investigating the effect of transcendental meditation on blood pressure: a systematic review and meta-analysis. J Hum Hypertens. 29(11): 653-62.

Bhardwaj, R. S., Koul, P., \& Vidyasagar, K. (2020). A Systematic Review And Meta-Analysis Of Effectiveness Of Breathing Exercises On Blood Pressure Of Patients With Hypertension. International Journal of Science, Engineering and Management (IJSEM). 12 (5). 
Brazilian Society of Cardiology. (2016) $7^{\text {a }}$ Systemic Arterial Hypertension Guideline. Arq Bras Cardiol. 107(3): 30-33.

Brook, R. D., Appel, L. J., Rubenfire, M., Ogedegbe, G., Bisognano, J. D., Elliott, W. J., et al. (2013) Beyond medications and diet: alternative approaches to lowering blood pressure: a scientific statement from the american heart association. Hypertension. 61(6): 1360-83.

Cernes, R., \& Zimlichman, R. (2017) Role of paced breathing for treatment of hypertension. Current hypertension reports. 19(6), 45.

Climov, D., Lysy, C., Berteau, S., Dutrannois, J., Dereppe, H., \& Brohet, C. (2014) Biofeedback on heart rate variability in cardiac rehabilitation: practical feasibility and psycho-physiological effects. Acta Cardiol. 69(3): 299-307.

Cohen, S., Kamarck, T., \& Mermelstein, R. (1983) A global measure of perceived stress. J Health Soc Behav. 385-396.

Del Paso, G. A. R., Cea, J. I., González-Pinto, A., Cabo, O. M., Caso, R., Brazal, J., et al (2006). Short-term effects of a brief respiratory training on baroreceptor cardiac reflex function in normotensive and mild hypertensive subjects. Appl Psychophysiol Biofeedback. 31(1): 37-49.

Elavally, S., Ramamurthy, M. T., Subash, J., Meleveedu, R., \& Venkatasalu, M. R. (2020) Effect of nurse-led home-based biofeedback intervention on the blood pressure levels among patients with hypertension: Pretest-posttest study. Journal of family medicine and primary care. 9(9), 4833-4840.

Fonkoue, I. T., Marvar, P. J., Norrholm, S. D., Kankam, M. L., Li, Y., DaCosta, D., Rothbaum, B. O., \& Park, J. (2018) Acute effects of device-guided slow breathing on sympathetic nerve activity and baroreflex sensitivity in posttraumatic stress disorder. American Journal of Physiology-Heart and Circulatory Physiology. 315(1): 141-149.

Goessl, V. C., Curtiss, J. E., \& Hofmann, S. G. (2017) The effect of heart rate variability biofeedback training on stress and anxiety: a meta-analysis. Psychol Med. 47(15): 2578-2586.

Gomes, J. S., Coghi, M. F., \& Coghi, P. F. (2014) Biofeedback cardiovascular e suas aplicações: revisão de literatura. Av Psicol Latinoam. 32 (2): $199-216$.

Greenberg, I., Stampfer, M. J., Schwarzfuchs, D., \& Shai, I. (2009) Adherence and success in long-term weight loss diets: the dietary intervention randomized controlled trial (DIRECT). J Am Coll Nutr. 28(2): 159-68.

Hamilton, M. (1959) The assessment of anxiety states by rating. Br J Med Psychol. 32(1): 50-55.

Joseph, C. N., Porta, C., Casucci, G., Casiraghi, N., Maffeis, M., Rossi, M., et al (2005). Slow breathing improves arterial baroreflex sensitivity and decreases blood pressure in essential hypertension. Hypertension. 46(4): 714-718.

Kearney, P. M., Whelton, M., Reynolds, K., Muntner, P., Whelton, P. K., \& He, J. (2005). Global burden of hypertension: analysis of worldwide data. Lancet. 365(9455): 217-223.

Lee, J., Kim, J. K., \& Wachholtz, A. (2015). The benefit of heart rate variability biofeedback and relaxation training in reducing trait anxiety. Hanguk Simni Hakhoe Chi Kongang. 20(2): 391.

Lehrer, P. M., Vaschillo, E., Vaschillo, B., Lu, S. E., Eckberg, D. L., Edelberg, R., et al (2003). Heart rate variability biofeedback increases baroreflex gain and peak expiratory flow. Psychosom Med. 65(5): 796-805.

Moura, R. R., \& Mendes, T. (2016) Contribuições da Técnica Coerência Cardíaca: Um estudo de revisão. Rev Cien Escol Estad Saud Publ Cândido SantiagoRESAP. 2(3): 163-177.

Neto, A. R. N. (2010) Biofeedback em terapia cognitivo-comportamental. Arq. Med. Hosp. Fac. Cienc. Med. Santa Casa São Paulo. 55(3): 127-32.

Nolan, R. P., Floras, J. S., Harvey, P. J., Kamath, M. V., Picton, P. E., Chessex, C., et al. (2010) Behavioral neurocardiac training in hypertension: a randomized, controlled trial. Hypertension. 55(4): 1033-1039.

Palomba, D., Ghisi, M., Scozzari, S., Sarlo, M., Bonso, E., Dorigatti, F., et al. (2011) Biofeedback-assisted cardiovascular control in hypertensives exposed to emotional stress: a pilot study. Appl Psychophysiol Biofeedback. 36(3): 185.

Prinsloo, G. E., Rauch, H. G., Lambert, M. I., Muench, F., Noakes, T. D., \& Derman, W. E. (2011). The effect of short duration heart rate variability (HRV) biofeedback on cognitive performance during laboratory induced cognitive stress. Applied Cognitive Psychology. 25(5): 792-801.

Reis, R. S., Hino, A. A., \& Añez, C. R. (2010) Perceived stress scale: reliability and validity study in Brazil. J Health Psychol. 15(1): 107-114.

Reiner, R. (2008) Integrating a portable biofeedback device into clinical practice for patients with anxiety disorders: Results of a pilot study. Appl Psychophysiol Biofeedback. 33(1): 55-61.

Santo, H. E., \& Daniel, F. (2017) Calcular e Apresentar Tamanhos do Efeito em Trabalhos Científicos (1): As Limitações do P < 0,05 Na Análise de Diferenças de Médias de Dois Grupos. Revista Portuguesa de Investigação Comportamental e Social. 1(1): 3-16.

Sharma, M., \& Rush, S. E. (2014) Mindfulness-based stress reduction as a stress management intervention for healthy individuals: a systematic review. $J$ Evid Based Complementary Altern Med. 19(4): 271-286.

Sherlin, L., Gevirtz, R., Wyckoff, S., \& Muench, F. (2009) Effects of respiratory sinus arrhythmia biofeedback versus passive biofeedback control. International Journal of Stress Management. 16(3): 233.

Trudel-Fitzgerald, C., Gilsanz, P., Mittleman, M. A., \& Kubzansky, L. D. (2015). Dysregulated Blood Pressure: Can Regulating Emotions Help? Curr Hypertens Rep. 17(12): 92.

Tsai, P., Chang, N. C., Chang, W. Y., Lee, P. H., \& Wang, M. Y. (2007) Blood pressure biofeedback exerts intermediate-term effects on blood pressure and pressure reactivity in individuals with mild hypertension: a randomized controlled study. J Altern Complement Med. 13(5): 547-554. 
Research, Society and Development, v. 10, n. 9, e56110918525, 2021

(CC BY 4.0) | ISSN 2525-3409 | DOI: http://dx.doi.org/10.33448/rsd-v10i9.18525

Unger, T., Borghi, C., Charchar, F., Khan, N. A., Poulter, N. R., Prabhakaran, D., et al. (2020). International Society of Hypertension global hypertension practice guidelines. Hypertension. 75(6), 1334-1357.

Veiga, E. V., Nogueira, M. S., Cárnio, E. C., Marques, S., Lavrador, M. A. S., Moraes, S. A., et. al. (2003) Avaliação de técnicas da medida da pressão arterial pelos profissionais de saúde. Arq Bras Cardiol. 80(1): 83-9.

Wang, S. Z., Li, S., Xu, X. Y., Lin, G. P., Shao, L., \& Zhao, Y. (2010) Effect of slow abdominal breathing combined with biofeedback on blood pressure and heart rate variability in prehypertension, J. Alternative Compl. Med. (16) 1039-1045.

Whelton, P. K., Carey, R. M., Aronow, W. S., CaseyJr, D. E., Collins, K. J., Himmelfarb, C. D., et al. (2018) ACC/AHA/AAPA/ABC/ACPM/AGS/APhA/ASH/ASPC/NMA/PCNA. Guideline for the Prevention, Detection, Evaluation, and Management of High Blood Pressure in Adults: A Report of the American College of Cardiology/American Heart Association Task Force on Clinical Practice Guidelines. Hypertension. 71: e13-e115.

Yau, K. K-Y., \& Loke, A. Y. (2021) Effects of diaphragmatic deep breathing exercises on prehypertensive or hypertensive adults: A literature review. Complementary Therapies in Clinical Practice. 43, 101315. 